\title{
Systematization modern devices for the protection of buildings and structures due to seismic impacts
}

\author{
Natalia Kolosova ${ }^{1}$, Evgenii Kolosov ${ }^{1}$ and Kamil Agishev ${ }^{2}$ \\ ${ }^{1}$ Peter the Great Saint-Petersburg Polytechnic University, Institute of Civil Engineering, 195220 \\ St.Petersburg, Russia \\ ${ }^{2}$ TÜV International RUS, 190000 St.Petersburg, Russia
}

\begin{abstract}
The various types of structures and devices used for seismic isolation and protection of buildings and structures are considered in this work. In this paper the authors consider and analyze both traditional and modern design and protection means of buildings under seismic conditions with a view to their classification. As a result of this research the authors suggest modern classification of device for seismic protection and seismic isolation. According to the authors, this classification will allow to take the necessary constructive solution for the construction of facilities in the earthquake area.
\end{abstract}

\section{The basic systematization of seismic protection methods}

Every year, there are about a million earthquakes throughout the world, but most of them are so small and go unnoticed. Really strong earthquake capable of causing extensive damage occur on the planet about once every two weeks. [1].

Since seismic hazard is very important problem for the construction industry, many scientists have tried to systematize the methods and ways to protect structures from earthquakes. All used methods of protection buildings and structures are divided into traditional and special [2].

Traditional methods of protection are the methods based on increasing the carrying capacity and the sustainability of the building through the use of various design and architectural - planning decisions.

The first such systematization was presented in the form of a diagram, in which all methods of protection are divided into active (special) and passive (traditional) methods of protection [3-5].

In the future, to protect structures from earthquakes have applied combinations of active and passive methods [6-8] (Fig.1). 


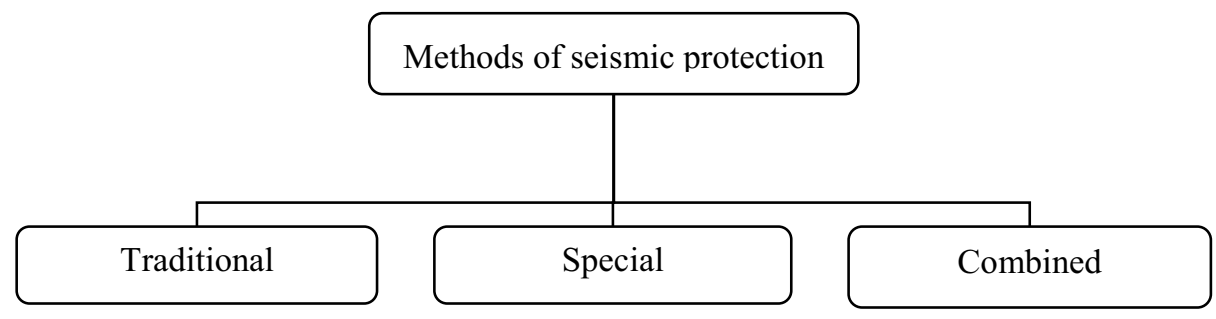

Fig. 1. Initial classification.

\subsection{Traditional methods of seismic protection}

As noted above, traditional passive methods of protection of buildings and structures are based on the principle of absence of special additional devices.

During design necessary to use a special constructive solutions:

- centrally symmetrical construction,

- elements of bearing structures should be equal in strength,

- to ensure the uniformity and monolithic character of construction,

- the architectural form of the building in the form of a circle, square, symmetric polygon,

Passive method of seismic protection generally leads to an increase in volume of the used materials, which in turn leads to an increase in weight and the inertial efforts.

With the development of the construction industry and the emergence of more complex building structures the above methods could not always be realize, required a new recommendation.

For example, for the construction of high multi-story facilities recommended to make a massive deep foundation; the long and not symmetrical buildings must be equipped with anti-seismic joints, providing the cutting of the building into separate pieces; in the presence of weak or fractured soils is recommended to carry out a partial or complete replacement [9].

Of course, these methods have led to positive results in some cases. However, as the experience of studying the consequences of strong earthquakes in Japan, Italy, China, Venezuela and other countries to ensure the full safety of buildings and structures using these recommendations is not possible [10].

In connection with this circumstance, the alternative (special) methods and means of increasing earthquake resistance intensively develop for the last 3-4 decades along with traditional methods of providing earthquake resistance.

\subsection{Special methods of seismic protection}

The ideas to create a special non-traditional method of providing seismic resistance based on well-known principles which include:

- natural frequencies of the structure compared to the predominant frequencies of seismic influence,

- foundation without a rigid connection with the construction,

- using dynamic vibration absorbers of different types, etc.

Special methods of seismic protection allow reducing the dynamic loads on the structure during the oscillation process by adjusting dynamic characteristics, thus reducing the resonance effect on the structure.

This effect can be achieved with the use of special seismic protection devices. 
For the first time the seismic protection device was used in 1909 by J. A. Calanterients. His system played the role of seismic isolation based on the principle of material sliding along material. As seismic isolation material, the author recommended the use the mica, talc or sand [5].

Also, should be noted the use of sliding basements, moving rollers, balls of different diameters as early experiments of special non-traditional devices [3-7].

In the 70 years of the twentieth century with the development of science, there was a rubber used as seismic isolation material in Japan [10]. This material was used in the construction of basements.

Further, was developed a new seismic protection element by vulcanization of the steel plate with rubber material. This element increases the vertical stiffness of the shock absorber.

In the last 20-25 years the use of nontraditional methods of seismic isolation has been widely developed. Currently there are more than 100 patented designs of seismic isolation in the world. Consider some in detail.

\subsubsection{Active seismic isolation systems}

The principle of operation of such systems based on the use of automatic control of power elements, which creating the dynamic effect [11].

The effectiveness of such trade is very high, and the system can be versatile enough to allow rapid changeover the virtually any seismic effects.

A good example of active systems trade is the latest development of the Japanese researchers called Japanese Levitating House System design by the company "Air Danshin Systems Inc" [10-14].

The Japanese designers reasoned that if the earthquake is affecting you, only when you stand on the ground, therefore, in a couple of centimeters from the ground is already quite safe. This concept formed the basis of the new "flying houses". A normal-looking house set on concrete earthquake resistant foundations and structure is placed around the system mechanisms: a sensor that detects the tremors and sends a signal to the compressor, that it began to pump under the building a large enough volume of air. To keep the house maintained its stability during levitation, the amount of air is regulated by means of the special valve.

As a result, the building gradually rises above the base, three centimeters and waits in this state, the cataclysm. Then it's returned to safely to his seat. Such a futuristic house has already acquired 88 private homes throughout Japan, and in the meantime, a development company is hoping for wider adoption of its technology.

Also, the installation of frames earthquake resistant foundation designed by scientists from Stanford is one of the latest developments. Heavy multi-store structures difficult to get to fly, but they can move, while still standing on the quaking earth.

Greg Deierlein and his colleagues have developed a special frame of steel, which can be strengthened on the walls like old buildings and those that are just being built [15]. This durable frame connects all the floors with basement - but not very strongly, and so that during an earthquake the walls can deviate in different directions, up or down.

The steel frame is prudently covered with network wires that return the walls to original position. In fact, the house moves to the beat with underground vibrations and earthquake energy is extinguished. The protection of buildings and structures under seismic impacts is devoted to the many works of domestic and foreign experts.

Currently, the number of objects constructed using various means of seismic isolation and seismic protection in industrialized countries amounts to many hundreds, while these 
include structures with a high degree of responsibility such as the reactor compartment of nuclear power plants, large bridges, high-rise buildings and others [16-22].

Taking into account the diversity of seismic isolation devices we have necessity to systematize them. The authors analyzed the available literature about spatial seismic isolation devices and created the first attempt of their systematization, taking into account the latest developments (Fig. 2).

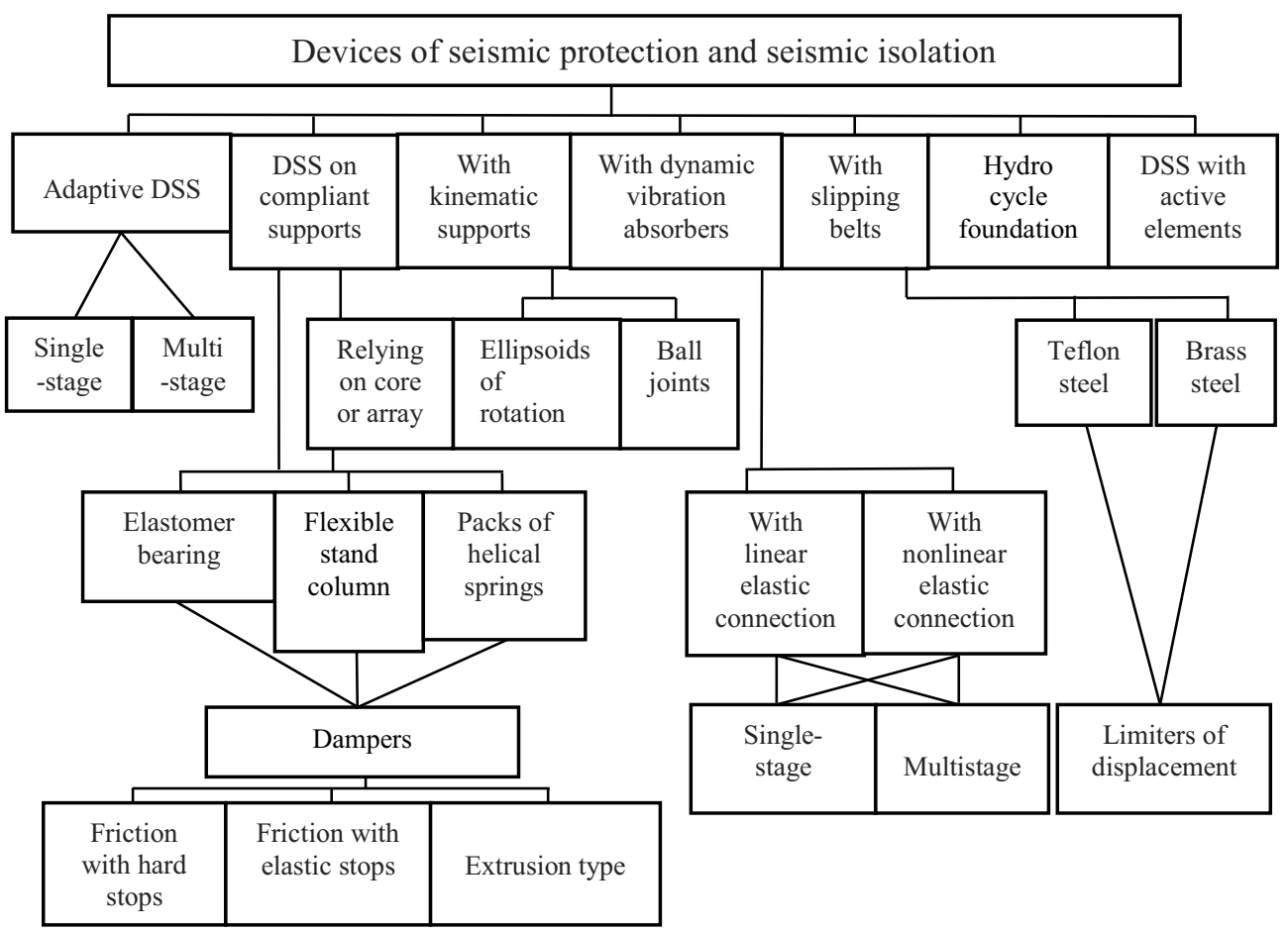

Fig. 2. Classification of devices of seismic protection and seismic isolation.

\subsection{Combined methods of special seismic protection}

Considering the different possibilities of traditional and special methods of protection of buildings and structures against seismic loads is also advisable to use a joint combination of traditional and special methods.

The Significant progress in the application of combined methods of protection was achieved by the American and Japanese scientists. They have achieved a reduction of destructive effects on building structures. $[6,10,16]$

Combining a set of different activities, traditionally recommended by the existing regulatory documents allows improve the bearing capacity of the building structure; significantly reduce the seismic loads on the structure, changing the dynamic stiffness or natural frequency of the building. Regulation of dynamic parameters allows to avoid resonance increasing of the vibration amplitudes of the structures and to reduce resonance effects. 
As special devices you may use methods of moving belts, various dampers, kinematic foundations, braced systems with flexible diaphragms, elastomeric bearings, spatial-plastic dampers and others.

In other words, we have to use a combined method of protection. However, it should be noted that this combination does not mean using only one of these methods.

In the case of the combined approach and if necessary it is possible to use several methods, both traditional and special techniques at the same time.

\section{Conclusion}

The aim of this work was to study and analyze the existing methods and devices used in the protection of buildings and structures against seismic loads and their systematization. In our opinion, systematization is an area of research which has own scientific value.

In the literature the systematization of seismic protection methods is shown separately either in the form of short circuits, either in the form of small textual descriptions. After analyzing the available material, the authors of this article offer a more complete version of the systematization of modern methods and devices of seismic protection and seismic isolation of structures.

This work is aimed at practical application and will help participants of the construction process to orient correctly in the variety of available funds and choose the optimal method for protecting buildings from seismic effects in certain conditions. The authors intend to continue the study of methods and devices for seismic protection.

\section{References}

1. K.M. Shedlock, L.C. Pakiser, Earthquakes. In science for changing world (2007), available on internet: http:// Pubs.Usgs.gov/gip/earthquakes

2. A. R. Arutyunyan, Modern methods of seismic isolation of buildings \& structures, MAG CIVIL ENG, 3 (13), (2010)

3. J. M. Eisenberg, A. I. Neumann, A. D. Abakarov, etc, Adaptive system for seismic protection of structures (Moscow, 1978)

4. V. S. Polyakov, The question about the effectiveness of the dynamic damper of oscillations under seismic forces, Construction mechanics and calculation of structures, 5, 49-53 (1980)

5. A. M. Uzdin, Basic theory of seismic \& earthquake-proof construction of buildings \& structures, 176 (St. Petersburg, 1993)

6. R.I. Skiner, W.H. Robinon, G.H. McVerry, Introduction to seismic isolation (New Zealand, 1993)

7. J. M. Eisenberg, V. I .Smirnov, etc, Effective system of seismic isolation. Research, design \& construction, SB. VNIINTPI, Earthquake-resistant construction. Safety of structures, 1, 31-37 (2002).

8. V. A. Lyadsky, Earthquake-resistant buildings, Abstracts of scientific-research works of students and postgraduates of SPbSPU (2008)

9. J. M. Eisenberg, Seismic isolation of tall buildings, Earthquake-resistant construction. Safety of structures. 4, 41-43 (2007)

10. A. Kato, S. Moro, M. Morishita, Development Program of Three-Dimensional Seismic Isolation for Advanced Reactor System in Japan. SMIRT-17, K 10-1, 1-8 (2003) 
11. O. A. Savinov, Dynamic problems of construction machinery, St. Petersburg (1993)

12. J. D. Cherepansky, Comparative analysis of the seismic isolation foundations reference type, Earthquake-resistant construction. Safety of structures, 5, 31-34, (2004)

13. G. E. Avidan, E. A. Carlina, Vibration characteristics of buildings with seismic isolation foundations, Earthquake resistant construction. Safety of structures, 1, 42-44 (2008)

14. D. Rashid, E.S. Kolosov, N.B. Kolosova, T.N. Soldatenko, Evaluation's methods of the seismic stability of buildings and structures in the Gaza Strip (2016) http://www.crcnetbase.com/doi/book/10.1201/9781315393827

15. H. Burton, G. Deierlein, Simulation of Seismic Collapse in Nonductile Reinforced Concrete Frame Buildings with Masonry Infill, J STRUCT ENG, 8, 140, (2014)

16. J. Barr, The seismic safety of bridges: A view from the design office, 12th European Conference on Earthquake Engineering (Oxford, UK, 2002)

17. A. D. Abakarov, Study of the seismic response \& evaluation of rational parameters of seismic isolation systems with sliding zone under seismic loading, Earthquakeresistant construction. Safety of structures, 6, 31 -34 (2003)

18. A.S. Scalat, Evaluation of existing building in Israel for seismic hazard, Wiley Inter Science. Earthquake Engineering Dynamics, 6, Issue 3, 317- 325 (2007)

19. Wiggins, D.F. Noran, Earthquake safety in the city of Long Beach (California 2008), available on internet: www.amazon.com/Earthquake

20. A.S. Hokmabadi, B. Fatahi, B. Samali. Assessment of soil-pile-structure interaction influencing seismic response of mid-rise buildings sitting on floating pile foundations. Computers and Geotechnics, 172-186 (2014)

21. V.S. Vorob'yev, E.I. Valkner. Features of designing zero-cycle constructions for multistorey block of flats in seismic regions, All-Russian Scientific Conference of Students, PhD Students and Young Scientists, 204-206 (Novokuznetsk, SGIU, 2015)

22. H. Qu, R. Li, H. Hu, H. Jia, J. Zhang, An approach of seismic design for sheet pile retaining wall based on capacity spectrum method. Geomechanics and Engineering, 309-323 (2016) 